East African Medical Journal Vol. 85 No. 9 September 2008

KNOWLEDGE, ATTITUDE AND USE OF LABOUR PAIN RELIEF METHODS AMONG WOMEN ATTENDING ANTENATAL CLINIC IN NAIROBI

V. Mung'ayi, MBChB, MMed (Anaesthesia), Fell. CCM. Senior Instructor, D. Nekyon, MBChB, MMed (Anaesthesia), Senior Instructor, Department of Anaesthesia and R. Karuga BSc, MPH, Research Support Unit, Aga Khan University Hospital, P. O. Box 30270-00100, Nairobi, Kenya

Request for reprints to: Dr. V. Mung'ayi, Department of Anaesthesia, Aga Khan University Hospital, P. O. Box 3027000100, Nairobi, Kenya

\title{
KNOWLEDGE, ATTITUDE AND USE OF LABOUR PAIN RELIEF METHODS AMONG WOMEN ATTENDING ANTENATAL CLINIC IN NAIROBI
}

\author{
V. MUNG'AYI, D. NEKYON and R. KARUGA
}

\begin{abstract}
Background: Labour analgesia has rapidly gained popularity in obstetric practice. Low usage in the developing world has raised concern.

Objectives: To assess the knowledge, attitude and use of labour pain relief methods in women attending antenatal clinic in Nairobi.

Design: A prospective study.

Setting: Aga Khan University Hospital, a teaching and referral hospital in Nairobi, Kenya.

Subjects: Two hundred and two consecutive expectant mothers attending antenatal clinic at the Aga Khan University Hospital, Nairobi.

Results: Fifty six per cent of the participants had knowledge about labour pain relief methods. Friends, the antenatal clinic and books/leaflets were the major source on information. Ninety per cent indicated they would intend to have some form of labour pain relief at their next delivery. Eighteen percent had been offered some form of pain relief at their last delivery with $82 \%$ of those offered having effective pain relief $\quad(P<0.001)$.

Conclusions: While most of our participants were well educated, level of knowledge of labour analgesia is still low. Use of labour analgesia is also still quite low in comparison to the western World. It is recommended that obstetricians and anaesthetists participate in knowledge dissemination and setup of dedicated labour analgesia services in this region.
\end{abstract}

\section{INTRODUCTION}

Natural child birth is associated with labour pain that exceeds expectations. The scientific definition of pain was introduced by the International Association for the Study of Pain. Pain is an unpleasant sensory and emotional experience associated with actual or potential tissue damage, or described in terms of such damage (1).

Bonica (2) has defined acute pain as a complex constellation of unpleasant sensory, perceptual, and emotional experiences and certain associated autonomic, psychological, emotional, and behavioural responses.

Lowe (3) has described the nature of labour pain which begins with an understanding of the nociceptive stimuli that may be centrally perceived by the parturient and called pain. During the dilatation phase of labour (first stage), it is the visceral pain that predominates with pain (nociceptive) stimuli arising from the mechanical distension of the lower uterine segment and cervical dilatation. High threshold myometrial mechanoreceptors may also generate nociceptive stimuli in response to uterine contractions especially in long, protracted labours. The increasing intensity of pain commonly observed with the progression of the dilatation may be partially attributable to a lowered activation threshold in the mechanoreceptors, and the chemoreceptor stimulation produced by repeated stimulation of uterine contractions. As the pelvic or descent phase of labour progresses (late first stage and second stage), somatic pain predominates from distension and traction on pelvic structures surrounding the vaginal vault and from distension of the pelvic floor and perineum. 
The negative physiologic effects of labour pain are believed to originate mainly in alterations in the maternal respiratory pattern and the catecholamine mediated stress response.

Brownridge (4) has reviewed the potential physiological effects of severe labour pain which may include increased oxygen consumption and hyperventilation with hypocarbia and respiratory alkalosis, and autonomic stimulation and catecholamine release with gastric inhibition and increased gastric acidity, lipolysis, increased peripheral vascular resistance, cardiac output, and blood pressure, decreased placental perfusion and incoordinate uterine activity. At the extreme end of the spectrum, these responses are hypothesised to produce maternal metabolic acidaemia, fetal distress and dysfunctionallabour. However Brownridgestates that "such effects may be largely innocuous during the course of an uncomplicated labour".

Several surveys have been conducted that show a large proportion of women go through labour using various methods of pain relief (5 - 7).

In contrast to women in Western countries, the majority of women in the developing world including Africa have no access to pain relief methods in labour $(8,9)$. In order to assess the magnitude of the problem, we conducted a questionnaire survey of antenatal women regarding their knowledge, attitude and use of labour pain relief methods.

\section{MATERIALS AND METHODS}

Approval from the Aga Khan University Hospital Research and Ethics Committee for our survey was sought and obtained prior to commencement of the survey.

The survey was conducted in May, 2007. We surveyed 202 women attending antenatal clinic at the Aga Khan University Hospital, Nairobi over a period of 20 days using a questionnaire. The questionnaire captured their demographics, knowledge and attitude of labour pain relief methods.

An investigator was available to explain any technical terms in the questionnaire that the participants did not comprehend. Both primigravida and parous women were included in the survey. All descriptive and analytical statistics were performed using Intercooled Stata (StataCorp 200. Stata Statistical Software: Release 9. College Station, TX: Stata Corporation.). A p-value of $<0.05$ was considered significant for all statistical tests.

\section{RESULTS}

In May, 2007, 202 consecutive women attending the antenatal clinic at our hospital were enrolled in our survey. All of them completed the provided questionnaires. Characteristics of the women interviewed are shown in Table 1.

Themajority of the women wereyoung (mean age 27 years), had a college level of education (52\%) and were parous $(65 \%)$. Fifty six per cent of the participants had knowledge of labour pain relief methods. Among participants who had knowledge of labour analgesia, friends, the antenatal clinic and books/ leaflets were the major source on information.

Table 1

Baseline variables of interviewed women $(n=202)$

\begin{tabular}{lcc}
\hline Variable & No. & $(\%)$ \\
\hline Mean age & 27 & - \\
Primary & 5 & 2 \\
Secondary & 24 & 12 \\
College & 105 & 52 \\
University & 68 & 34 \\
Primigravida & 71 & 35 \\
Multiparous & 131 & 65 \\
Knowledge of labour & & \\
pain relief method & 111 & 56 \\
Doctor & 14 & 13 \\
Antenatal classes & 28 & 25 \\
Friends & 26 & 23 \\
Book/leaflets & 35 & 32 \\
Internet & 8 & 7 \\
\hline
\end{tabular}

There was no significant relationship between level of education and knowledge of pain relief methods, $\mathrm{P}=0.494$. Ninety four per cent of the parous women had experienced pain at their last delivery, with $54 \%$ of them having felt severe pain, $32 \%$ moderate pain, eight per-cent mild pain and six percent had not experienced any pain. A minority of the parous women $(18 \%)$ had been offered any form of pain relief at their last delivery. Of those who had been offered pain relief, a majority of $82 \%$ had effective pain relief.

Table 2 shows the pain experience and management. There was a significant relation between pain relief administration and effectiveness, $\mathrm{P}<0.001$. The majority of the participants in our survey, $90 \%$, indicated they would intend to have some form of labour pain relief at their next delivery so long as they were assured it would be safe for them and their babies. Eight per cent declined and two per cent were unsure whether they would like pain relief at their next delivery. 
Table 2

Pain experience and management $(n=131)$

\begin{tabular}{lcc}
\hline Variable & No. & $(\%)$ \\
\hline No pain & 8 & 6 \\
Mild pain & 10 & 8 \\
Moderate pain & 42 & 32 \\
Severe pain & 71 & 54 \\
Offered pain relief & 22 & 18 \\
Not offered pain relief & 109 & 82 \\
& & \\
Offered pain relief $(\mathrm{n}=22)$ & & \\
$\quad$ Pain relief effective & 18 & 82 \\
$\quad$ Pain relief not effective & 4 & 18 \\
\hline
\end{tabular}

\section{DISCUSSION}

Our study shows that just over half of women attending antenatal clinic at the university hospital had knowledge about labour pain relief methods. This is comparable to findings of a similar study conducted in South Africa by Mugambe et al (10). Minhas et al (9) found higher figures of knowledge about labour pain relief methods at a university hospital in Pakistan. Other studies in Africa by Okeke et al (11) and Akpan et al (12) have shown much lower levels of knowledge of 38.9 and $4.5 \%$ respectively.

A striking finding in our setting was that while most of our survey participants were of college or university education, this was not associated with a higherlevel of knowledgeonlabour pain relief methods overall. This could be due tolack of emphasis on family based subjects in college and university curricula and shows the substantial unmet need for relevant health related information even among educated women.

Friends, booklets / leaflets and the antenatal clinic were the main sources of information in our survey. Stewart et al (13) found comparable results in their study. Although more than half of the women in our survey knew about labour analgesia, only a small percentage availed this service. This compares with a study by Onah et al (14) which showed that only $22.1 \%$ of parturients received some pain relieving drug during labour.

This low availability in our study could be due to extra expenses that may be involved in availing this service. Cultural and religious practices, lack of adequate information on safety and use of labour analgesia during antenatal clinics or via leaflets could also explain the low usage. There are no hospitals offering a well established labour analgesia service in our region. This could be another explanation for low availability of labour analgesia in our setup.

Although only a small percentage of our participants had received labour analgesia at their last delivery, it was reported as having been effective.
The level of effectiveness was comparable to findings elsewhere.

Findley et al (5) has shown that with pharmacological labour analgesia methods, entonox was helpful to about $85 \%$ of the women who used it, opiates provided $85 \%$ of women who used them with a good experience of pain relief while over $90 \%$ of the women who used epidural analgesia found it good or very good and $85 \%$ would choose to use it again. In our study the various pharmacological labour analgesia methods had a comparable level of effectiveness. Amajority of participants in our survey expressed willingness to have labour analgesia at their next delivery if safety was assured for them and their babies.

What do the present findings add to knowledge about the relationship between social and educational context, knowledge, demand and use of pain relief methods in labour? Our patients might be considered to be socio-culturally located within a transition from traditional social norms for coping with labour pain, to a cultural milieu heavily influenced by Western values and expectations. Our findings suggest that the expected linkages between education in general, specificknowledge of pain relief methods, demand for and use of services are highly fragmented. However, it is clear that when offered relevant information on pain relief options our patients are certainly interested in these options. The implication for maternity care providers in urban settings of developing countries such as ours is that specific measures are needed to overcome the substantial information, access and service delivery gaps that currently exist.

Our survey has some limitations. The results of our study cannot be generalised as it was conducted in only one centre and most of the study participants were educated and employed. This would have had an impact on their level of knowledge, attitude and use of labour analgesia as compared to a similar survey conducted elsewhere. Also, the survey method was not able to provide the detailed insight into the meaning of labour pain for women that would be obtained through a qualitative study.

In conclussion, our study has shown that despite a big percentage of women attending our antenatal clinic being well educated, knowledge on labour analgesia methods is still below the Western World levels. Friends, books/leaflets and the antenatal classes are the most common source of information. We recommend reinforcement of these sources and urge the obstetricians and anaesthetists to become moreactively involved inlabour analgesia knowledge dissemination. A majority of the participants in our study have shown willingness to have a labour analgesia at their next delivery. Setting up dedicated labour analgesia services in this region would therefore go a long way in alleviating labour pain and its associated suffering. 


\section{REFERENCES}

1. Merskey, H. Pain terms: a list with definitions and a note on usage. Recommended by the International Association for the Study of pain (IASP) subcommittee on taxonomy. Pain. 1979; 6: 249-252

2. Bonica, J.J. Definitions and taxonomy of pain. In: Bonica J.J, editor. The management of pain. 2nd edition. Philadelphia: Lea \& Febieger; 1990; pI8-27.

3. Lowe, N.K. The nature of labour pain. Am. J. Obstet. Gynecol. 2002; 186: S16- S24.

4. Brownridge, P. The nature and consequences of childbirth pain. Eur. J. Obstet. Gynecol. and Reprod. Biol. 1995; 59: S9-S15.

5. Findley, I. and Chamberlain, G. ABC of labour care: Relief of pain. Brit. Med. J. 1999; 318: 927-930.

6. Oystan, I. Obstetrical anaesthesia in Ontario. Can. J. Anaesth. 1995; 42: 1117-1125.

7. Stamer, U.M., Messersschmidt, A., Wulf, H. and Hoeft, A. Practice of epidural analgesia for labour pain: a German survey. Eur. J. Anaesthesiol. 1999; 16: 308-314.

8. Chan, Y.K. and Ng, K.P. Survey of regional analgesia and anaesthesia for obstetrics in selected countries in the Far East. Int. J. Obstet. Anesth. 2000; 9: 225-232.
9. Minhas, M.R., Kamal, R., Afshan, G. and Raheel, $\mathrm{H}$. Knowledge, attitude and practice of parturients regarding epidural analgesia for labour in a university hospital in Karachi. J. Pak. Med. Assoc. 2005; 55: 63-66.

10. Mugambe, J.M., Nel, M., Hiemstra, L.A. and Steinburg, W.J. Knowledge of and attitude towards pain relief during labour of women attending Cecilia Makiwane Hospital's antenatal clinic, South Africa. South Afr. Fam. Pract. 2007; 49: 16.

11. Okeke, C.I., Merah, N.A., Cole, S.U., et al. Knowledge and perception of obstetric analgesia among prospective parturients at the Lagos university Teaching Hospital. Niger Postgrad. Med. J. 2005; 12: 258-261.

12. Akpan, S.G., Eshlet, A.I., Ilori, L.U., et al. Attitude of Nigerian mothers to labour pain and its relief. Mary Slessor J. Med. 2003; 3: 12-13.

13. Stewart, A., Sodhi, V., Harper, N., et al. Assessment of the effect upon maternal knowledge of an information leaflet about pain relief in labour. Anaesthesia. 2003; 58: 1015-1019.

14. Onah, H.E., Obi, S.N., Oguanuo, T.C., et al. Pain perception among parturients in Enugu, South Eastern Nigeria. J. Obstet. Gynaecol. 2007; 27: 585-588. 